
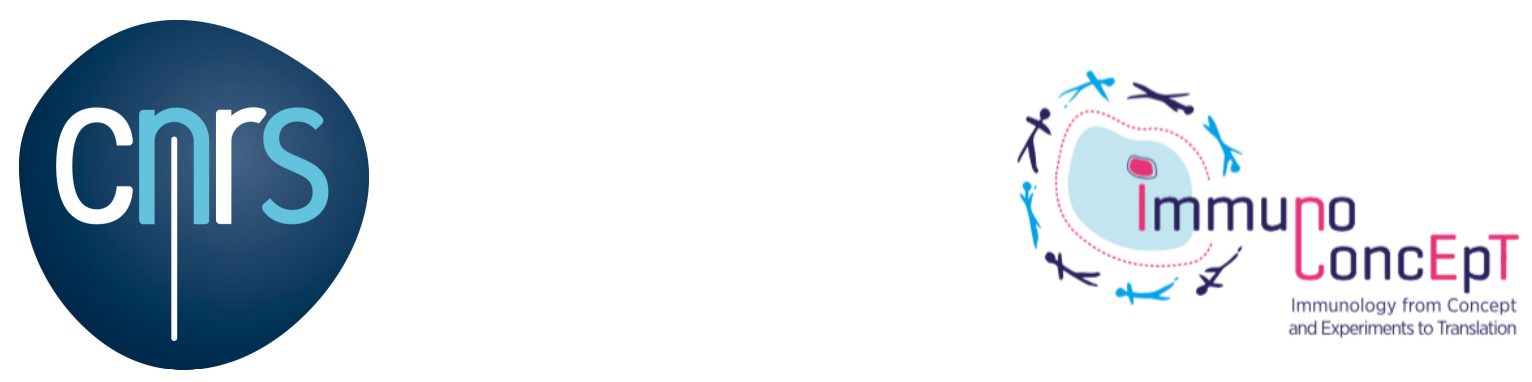

\title{
Organisms or biological individuals? \\ Combining physiological and evolutionary individuality
}

(Special issue of Biology \& Philosophy on biological individuality, T. Pradeu, ed.)

Final version published in Biology \& Philosophy, November 2016, 31(6), pp 797-817, http://link.springer.com/article/10.1007/s10539-016-9551-1

\section{Thomas Pradeu}

(ImmunoConcEpT, UMR5164, CNRS \& University of Bordeaux, 146 rue Léo Saignat 33076 Bordeaux, France, thomas.pradeu@u-bordeaux.fr)

\begin{abstract}
The definition of biological individuality is one of the most discussed topics in philosophy of biology, but current debate has focused almost exclusively on evolution-based accounts. Moreover, several participants in this debate consider the notions of a biological individual and an organism as equivalent. In this paper, I show that the debates would be considerably enriched and clarified if philosophers took into account two elements. First, physiological fields are crucial for the understanding of biological individuality. Second, the category of biological individuals should be divided into two subcategories: physiological individuals and evolutionary individuals, which suggests that the notions of organism and biological individual should not be used interchangeably. I suggest that the combination of an evolutionary and a physiological perspective will enable biologists and philosophers to supply an account of biological individuality that will be both more comprehensive and more in accordance with scientific practices.
\end{abstract}




\section{Introduction}

Biological individuality is one of the main topics of recent philosophy of biology (Hull 1978; Hull 1980; Sober 1991; Hull 1992; Wilson 1999; Gould and Lloyd 1999; Wilson 2005; Okasha 2006; Godfrey-Smith 2009; Clarke 2011; Pradeu 2012; Bouchard and Huneman 2013; Wilson and Barker 2013). Yet philosophers of biology have typically raised the problem of biological individuality (i.e., What, in the living world, constitutes a relatively well delineated and cohesive unit?) from the point of view of evolutionary biology, leaving aside many biological fields where that problem has also played a central role (Pradeu, Editorial introduction, this special issue). There are, in fact, many different ways, in the living world, to count as one individual. Evolutionary biology, developmental biology, immunology, the neurosciences, genetics, alongside several other fields of contemporary biology, talk about biological individuality (Wilson 1999), and do so in various - and sometimes conflicting - ways. Confronting and articulating these different perspectives is an important (if arduous) task, which is likely to require the collaborations of biologists and philosophers of biology.

The pre-eminence of evolutionary approaches to biological individuality has had two significant and unwelcome consequences. First, we find a conceptual reduction of the notion of biological individual to the notion of evolutionary individual. Second, we encounter a conceptual misidentification of biological individuals with organisms, as if these two notions had the same meaning. In the present paper, I would like to argue that the three concepts ("biological individual", "evolutionary individual", and "organism") must be distinguished (see Figure 1), against recent attempts, by biologists and philosophers, to claim that they are equivalent (e.g., Queller and Strassmann 2009; West and Kiers 2009; Clarke 2013). I will try to show that clarifying the differences between these concepts leads to a richer, more comprehensive, conception of biological individuality, by which philosophers can better reflect how biologists themselves understand this notion. I defend five theses in this paper:

i) Biological individuality is a multifaceted notion, which needs to be understood from the point of view of several biological fields, evolutionary biology being only one of them;

ii) Physiological approaches to biological individuality have a long history and are fundamental to the understanding of biological individuality;

iii) The categories of "organism" and "biological individual" are not equivalent, and should therefore not be used interchangeably;

iv) One physiological field, immunology, can play a particularly crucial role in the definition of biological individuality, because of the constant surveillance by the immune system of the bodily constituents and its consequent contribution to the delineation of the organism's boundaries;

v) A satisfying concept of biological individuality requires the articulation of different approaches to biological individuality, particularly a physiological and an evolutionary approach.

The general point of this paper - about the importance of distinguishing physiological individuals and evolutionary individuals has been made elsewhere (Sober 1991; Hull 1992; Pradeu 2010; Godfrey-Smith 2013) - but it has failed to convince some philosophers and biologists. My aim here is to make the arguments for this claim more explicit, in the hope of convincing them. 
Although the present paper suggests a distinction between physiological individuality and evolutionary individuality, these dimensions by no means exhaust the diversity of the concept of biological individuality. Important work has been done, for example, on ecological individuality (Eldredge 1984; Huneman 2014), and several other fields (e.g., the cognitive sciences) also have much to say about biological individuality. Ultimately, philosophers of biology should consider the lessons stemming from various biological fields about biological individuality, confront and synthesize them, with the aim of building a unified account. This paper tries to go beyond mere pluralism by insisting that it is useful not only to describe the different ways biologists talk about biological individuality, but also to confront these distinct and sometimes divergent perspectives, in order to integrate them into a richer and more unified framework ${ }^{1}$.

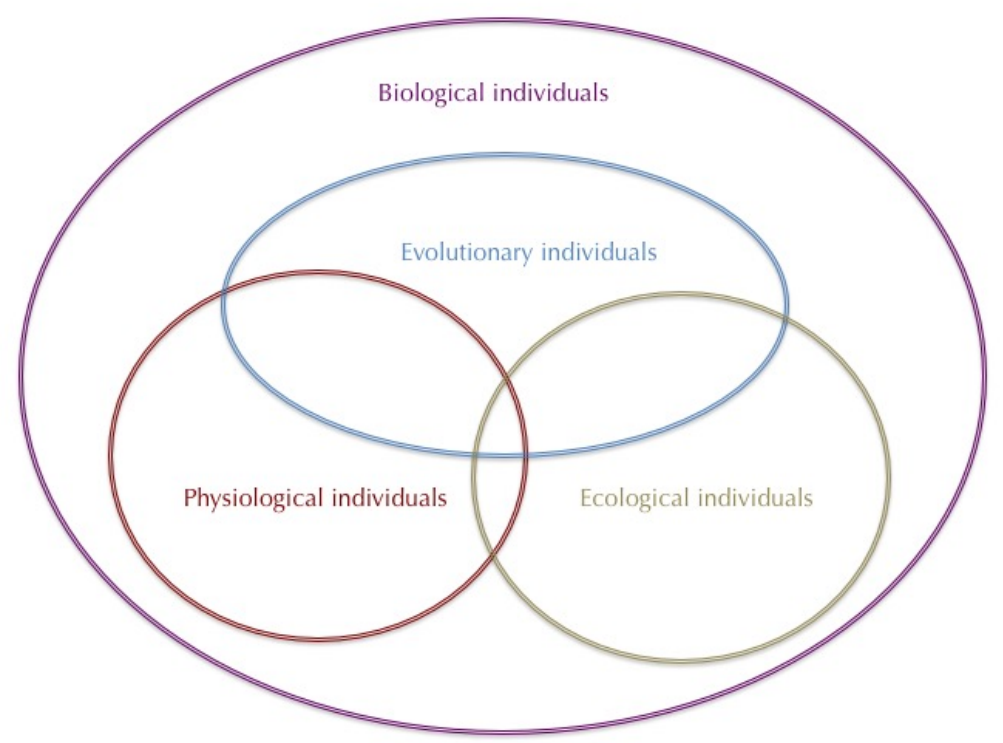

Figure 1. The broad category of "biological individual" can be divided into several subcategories, including "physiological individual" and "evolutionary individual", which only partly overlap (demonstrated below). Though they are not discussed in this paper, additional subcategories can be suggested, e.g., "ecological individual" (in which case it will be important to determine to what extent they overlap with the two other subcategories).

\section{The definition of physiological individuality and its importance for biology and the philosophy of biology}

At the most general level, the problem of biological individuality asks what, in the living world, constitutes a relatively well-delineated and cohesive unit. Biological boundaries are often fuzzy, and biological individuality is often question-dependent, coming in degrees, and being realized at different levels. Despite these uncertainties, it remains important, both

\footnotetext{
1 This can be done both within biology and between biology and other scientific fields, e.g., physics (Guay and Pradeu 2016).
} 
for philosophers and, in some contexts, for biologists, to identify biological individuals. One must, for example, be able to count offspring (Sober 1984; Clarke 2011) and distinguish growth from reproduction (Herron et al. 2013), to make interspecies comparisons (Pepper and Herron 2008), to distinguish organisms from parts of organisms (Herron et al. 2013), and to determine if tissues of one living thing can be transplanted into another living thing (Loeb 1930). For centuries, one important way to raise the problem of biological individuality has been to ask how distinct and heterogeneous components interact and constitute a cohesive whole, functioning collectively as a regulated unit that persists through time. This is the question of the unity of functioning, one which has been raised mainly within the realm of physiology. In what follows, I aim to examine this physiological account and to defend the view that it constitutes a crucial component of reflections on biological individuality, one that philosophers of biology cannot neglect.

Physiology, the "science of functions and constants of the functioning of living organisms" (Canguilhem 1994a), centres on unity of functioning. Physiological individuality consists in the interactions between bodily components and the regulation of these interactions, particularly through control over variations. Claude Bernard, one of the founders of modern physiology, was deeply concerned with this problem (Holmes 1986; Canguilhem 1994b; Noble 2008). Bernard built on the work of several previous thinkers, who, in the first half of the $19^{\text {th }}$ century, had suggested that, sometimes, what appeared as a living unit should be seen as a plurality of elements. This idea, already expressed by Goethe in $1807^{2}$, was strengthened by the formulation of the cell theory (by Schwann, Remak and Virchow, in particular) (Duchesneau 1987; Bechtel 2006). Thus, we find Virchow (1978 [1858]) writing: "What is an organism? A society of living cells, a tiny well-ordered state."

Continuing this line, Bernard sought to determine the most fundamental level of physiological study. According to him, the most crucial and characteristic phenomenon of life was nutrition - a broad and encompassing concept. By "nutrition", Bernard meant the process of destruction and construction that insures the persistence of a living being ${ }^{3}$ (Bernard 1974). For Bernard, therefore, physiological units were persistent nutritive units which he called units of "organic creation." Physiological units could be found at several levels, key ones being the cell level ${ }^{4}$ and the multicellular organism level. The cell, in Bernard's view, was itself an organism, and the level at which most biological processes occurred. The multicellular organism was a society of cells, with the parts having a certain degree of anatomic autonomy but being at the same time functionally subordinated to the whole 5 . Functional unity was given by the "internal milieu", at the level of the whole organism (a view shared and extended by many later physiologists, particularly (Haldane 1929)). The internal milieu insured that modifications within the organism compensates

\footnotetext{
2 "Every living being is not a unity but a plurality", quoted by Claude Bernard (1974).

3 "Nutrition is the continuous mutation of the particles that constitute the living being" (what Bernard also calls "molecular renovation").

4 "La cellule est donc l'élément anatomique végétal et animal, l'organisme morphologique le plus simple dont soient constitués les êtres complexes."

5 "The complex organism is an aggregate of cells or elementary organisms, in which the life conditions of each element are respected and in which the functioning of each is nonetheless subordinated to the whole." (Bernard 1974).
} 
environmental changes that affect the organism, resulting in the maintaining of key constants (e.g., temperature, glucose level, etc.)

Therefore, Bernard raised the problem of physiological individuality, understood as a unit of functioning. For him, the aim of physiology was to determine how a functional life is maintained in the continuous flux of destruction and construction that characterizes any living thing.

The problem of physiological individuality (understood as the maintenance of a unit of functioning through time) has been central to physiology ever since Bernard. According to another major figure of modern physiology, Walter B. Cannon, physiology seeks to explain "the ability of living beings to maintain their own stability", and the explanation is to be found in the concept of homeostasis, i.e., the coordinated physiological reactions which actively maintain most of the steady states in the body, despite external changes (Cannon 1926; Cannon 1929) ${ }^{6}$. Similarly, reflecting on twentieth-century physiology, Perlman (2000) notes that the idea of the organism as an organized and functionallyintegrated individual is pivotal in physiology, a field that studies the "internal workings" and the "maintenance of homeostasis in the internal environment" in organisms. Recent views extend these physiological approaches to individuality via different conceptual and theoretical tools, from systems biology in cardiology (Noble 2006; Noble 2008) to control theory and systems dynamics theory in the study of inflammation (Kotas and Medzhitov 2015). Thus, the question of the unity of functioning and its maintenance through time despite constant environmental changes is one of the most central questions of physiology, at least from the $19^{\text {th }}$ century onward.

Thus construed, the notion of physiological individuality is very broad. The study of a physiological individual is the study of its life from conception to death. It incorporates key aspects of several different fields, particularly embryology (the description of the origination and maturation of living things $)^{7}$, anatomy (the exploration of biological form through the description of its component parts, such as tissues and organs) ${ }^{8}$, as well as immunology, the neurosciences, endocrinology, etc. ${ }^{9}$

Because of its high level of generality, the notion of a physiological individual remains sometimes vague. Nevertheless, it can be made more precise in different ways. One crucial

\footnotetext{
${ }^{6}$ The concept of homeostasis is still widely used in today's physiology, e.g. (Rowland 1998; Cowley 2003; Walz 2005; DiBona 2005). For a historical account, see (Cooper 2008).

${ }^{7}$ Of course, developmental individuality can be explored for its own sake in extremely stimulating ways (e.g., (Gottlieb 1992; Minelli 2011), but as soon as one conceives physiological individuality as concerning a unit of functioning from its beginning to its end, it includes the development of that unit.

${ }^{8}$ Historically, physiology has been construed, at least in part, against anatomy, with the idea that physiology was a dynamic science about biological functions while anatomy was a static science about biological structures (Canguilhem 1994a). This "autonomization" of physiology, obvious in the work of Claude Bernard (Bernard 1957), for example, took in fact more the form of an incorporation of the lessons of anatomy into the new science of the functions of organs, so much so that, today, anatomy and physiology are often considered as two sides of the same coin and taught together (e.g., Saladin 2011). Moreover, the incorporation of anatomy and embryology into physiology is explicit in the work of Claude Bernard (Bernard 1974). "Les travaux des physiologistes ont eu précisément pour résultat de faire tomber les barrières qui séparaient l'œuf, l'embryon et l'adulte, et de faire apparaître dans ces trois états l'unité d'un organisme pris à trois moments différents de sa course, mais toujours soumis à la même impulsion et gouverné par la même loi. »

${ }^{9}$ It is even related to at least some understandings of biological individuality in ecology, where the focus is on understanding the nature and extent of interactions among constituent parts within an ecosystem (Huneman 2014)
} 
aspect of physiological individuality (though not the only one) concerns metabolism. "Metabolism" refers to all the chemical reactions involved in maintaining the living state of cells and organisms, through the breakdown of molecules to obtain energy ("anabolism") and the synthesis of the compounds used by the cell ("catabolism"). Among biologists, the idea that metabolism is key to defining biological individuality has been prominent since the beginning of the $20^{\text {th }}$ century (e.g., Child 1915). In recent philosophy of biology, Dupré and O'Malley (2009) have suggested a distinction between two broad categories of living things - metabolic things and lineage-forming things (see also (Godfrey-Smith 2013)). Though I see the focus on metabolism as useful, I prefer to focus here on physiological units rather than metabolic units, because many processes studied by physiologists and related to the question of biological individuality ${ }^{10}$ are not described in metabolic terms (though they generally rely on the existence of underlying metabolic processes). In other words, physiological individuality includes, but is not reducible to, metabolic individuality. That said, the study of metabolism is one of the ways by which the notion of physiological individuality can be specified.

More generally, the biological disciplines that are the descendants of physiology including the neurosciences, endocrinology, and immunology - offer precise and specific lessons about what counts as a unit of functioning. In the next section, I show in detail how one of these fields (immunology) can contribute decisively to the definition of physiological individuality. As we will see, the claim that the concept of physiological individuality would be too vague to be scientifically and philosophically useful is unsubstantiated.

Though it is often associated, at least intuitively, with the idea of a multicellular organism (more on this below), physiological individuality can be realized at different levels. As with Claude Bernard, a major (perhaps even the main) physiological unit is the cell (including within a multicellular organism). Today, many biologists work on cell physiology (Tyson et al. 2001). Physiology can also deal with entities situated at higher levels, like integrative colonies of social insects (Turner 2000). For Turner, physiology is "the science of how living things work", and, in termites such as Macrotermes natalensis, one can say (following (Lüscher 1961)) that the mound functions for the colony as a colossal heart-lung machine (p. 195), and that the entire termite colony constitutes a physiological unit ${ }^{11}$.

Within philosophy of biology, physiological individuality has been much less discussed than evolutionary individuality, but it is gaining increasing prominence (e.g., (Pradeu 2008; Dupré and O'Malley 2009; Pradeu 2010; Godfrey-Smith 2013; Arnellos et al. 2013; Godfrey-Smith 2014) (see also Godfrey-Smith, this special issue). The important point made by these authors is that, in addition to evolutionary individuals, it is possible to identify physiological individuals, and that the two categories are distinct, because an entity can be an evolutionary individual without being a physiological individual, and vice versa (more on this below).

\footnotetext{
${ }^{10}$ For example, in developmental biology, the neurosciences, or immunology.

${ }^{11}$ In the second chapter of the book ("Physiology beyond the organism"), Turner (2000) says that the science studying these higher-level physiological units can be called "physiological ecology", "ecophysiology", or "environmental physiology" (p. 9). Later, he speaks of "superorganismal physiology" (p. 179). See also (Seeley 1995; Sober and Wilson 1998).
} 
Physiological approaches to biological individuality have been crucial for biologists, and philosophers of biology interested in the concept of biological individuality must take these approaches into account. As suggested, one classic objection of philosophers to physiology-based conceptions of biological individuality is that they would be too vague (Hull 1992). In the next section, I will show that one physiological field - immunology can make a critical contribution to the definition of a precise notion of physiological individuality.

\section{Delineating the physiological individual: An immunological perspective on biological individuality}

Physiological individuality concerns the processes that insure the cohesion of the different elements that constitute a functional living thing - the "glue" that brings together the heterogeneous elements into a cohesive whole. Immunology, one of the main fields of today's physiology, sheds a critical light on this question, and can therefore contribute decisively to a more precise definition of physiological individuality. My claim about the pivotal role of immunity in our understanding of physiological individuality is grounded in three main arguments (Pradeu 2012):

i) the immune system constitutes a discrimination mechanism, accepting some entities

in the organism and rejecting others, thus participating decisively in the delineation of the organism's boundaries;

ii) contrary to many bodily "systems" (e.g., digestive or respiratory), the immune system is truly systemic (it exerts its influence everywhere in the organism);

iii) all living things have an immune system, including prokaryotes, plants, invertebrates and vertebrates, so an immunity-based account of biological individuality applies to the whole living world.

After analysing how the notion of individuality has been central to immunology for more than a century, I show why the immune system can be said to play such a major role in biological individuality, and I suggest that philosophical investigations into biological individuality must take into account the lessons offered up by immunology.

Biological individuality has been a major issue for immunologists since at least the end of the $19^{\text {th }}$ century (Richet 1894; Richet 1913; Loeb 1930; Loeb 1937; Medawar 1957; Burnet 1962; Hamburger 1978), as emphasized by many historians of the field (Löwy 1991; Moulin 1991; Tauber 1991; Tauber 1994; Löwy 2003). Immunologists have suggested that the immune system is involved in the definition of biological individuality in at least three senses of "individuality" (Pradeu 2012):

a) Uniqueness: What makes each biological individual unique? (e.g., Medawar 1957);

b) Delineation: What are the boundaries of a biological individual? (Richet 1894; Burnet 1962);

c) Persistence: What insures that something remains the "same" biological individual despite constant change? (Burnet 1962, p. 38-41).

From a historical point of view, a major event for the construction of immunology as a scientific field is the advent of serious transplantation medicine. It is the study of transplantation that lead Leo Loeb, Peter Medawar and Frank Burnet, among others, to construct their reflections about biological individuality. Leo Loeb shows, in several papers (Loeb 1930; Loeb 1937; Loeb 1953) and in a long book entirely devoted to the topic of 
biological individuality (Loeb 1945), that there exist degrees of biological difference ("individuality differentials") among individuals, which reflect the uniqueness and unity of each individual, and explain the success or failure of grafts. Medawar, who shared the Nobel Prize with Burnet in 1960 for their work on immune tolerance to grafts, also examines the relation between transplantation and the uniqueness of the individual, an idea further explored by Jean Dausset, who demonstrated the existence of an histocompatibility system in humans (Dausset 1981) (see also (Hamburger 1978)). A striking realization at that time was that biological uniqueness is further reinforced by the fact that even genetically identical individuals have different immune systems (Pradeu 2012).

In most cases, this triple dimension of immunological individuality - uniqueness, delineation, and persistence - has been described within the framework of the self-nonself theory of immunity. This theory has complex roots, but it is clear that Burnet $(1960 ; 1962$; 1969) played a major role in its formulation and diffusion. In a nutshell, the self-nonself theory says that the immune system does not respond to endogenous constituents of the organism ("self"), while it rejects exogenous constituents ("nonself").

Research done in immunology since the 1980s, however, strongly suggests that the self-nonself framework is inadequate. The main difficulty is that the self-nonself theory grounds the question of the boundaries of a living thing in a question of origin: everything that comes from the outside triggers a rejection response, while everything that comes from the inside does not trigger an immune response. Yet self constituents can trigger immune responses in healthy conditions (Anderton and Wraith 2002; Wing and Sakaguchi 2010; Germain 2012; Wynn et al. 2013) (Sakaguchi 2000; Bouneaud et al. 2000; Stefanová et al. 2002; Savill et al. 2002; Taylor et al. 2004; Sakaguchi 2006; Zehn and Bevan 2006; Germain 2012; Okabe and Medzhitov 2016) (this aspect was anticipated by Jerne (1974), and has been discussed by Tauber (1994) and Cohen (2000)). Moreover, many nonself constituents, including many microbes (as shown by recent work on symbiosis), are not rejected by the immune system (Hooper and Gordon 2001; Chu and Mazmanian 2013). This suggests that immune tolerance is a central and universal phenomenon (Pradeu and Carosella 2006). Nevertheless, the self-nonself theory was importantly correct in saying that the immune system is pivotal for the definition of biological individuality. The immune system, as an acceptance/rejection mechanism, constantly monitors what is going on in a living thing, and it determines which elements will be part of that living thing, and which elements will be rejected. Thus, it plays a major role in the delineation of the organism's boundaries and in the continuous construction of its unity through time. This discrimination mechanism crucially differs from the idea of self-nonself distinction: what matters for the discrimination mechanism is only that some constituents are rejected while others are not, but, contrary to the self-nonself theory, this discrimination is not a question of origin since, as stated, many genetically foreign entities can be accepted by the immune system while many endogenous entities are routinely destroyed.

Such considerations make it possible to offer an immunology-based definition of physiological individuals. An immunological individual is a functionally-integrated whole made up of heterogeneous constituents that are locally interconnected by strong biochemical interactions and controlled by systemic immune interactions (Pradeu 2010). It encompasses all the constituents with which immune receptors interact and which are tolerated by the immune system, regardless of the origin of these constituents (many microorganisms, for example, are tolerated). Thus, this immunological criterion suggests that any entity which interacts regularly with the immune system and is not eliminated by it 
is part of the physiological individual. In other words, the physiological individual, immunologically, is the unit made of the association of a host and many microbes (those that are tolerated by the immune system, in accordance with the discrimination mechanism described above). If this view is correct, then all the criteria of the supposedly paradigmatic "unitary organisms" (genetic uniqueness, genetic homogeneity, and physiological autonomy) (e.g., Santelices 1999) are problematic.

Moreover, from the perspective presented here, recent research on symbiosis strengthens (rather than undermines) the immunological definition of biological individuality. The conception of a biological individual as endogenous and autonomous must be rejected, but not the idea of a biological individual in general - contrary to what Gilbert et al. (2012), for instance, have suggested. Quite the contrary, the immune system is pivotal to explain how entities of different origins can stick together and interact within a functional and cohesive whole (Sansonetti and Medzhitov 2009; Pradeu 2010; Chu and Mazmanian 2013).

This immunological approach to physiological individuality helps better define what the physiological individual is, what makes it unique, what its boundaries are, and how it persists through time. It helps decide perennial "fuzzy" cases - particularly about colonial organisms, social organisms, and host-microbe associations. In the numerous situations where perception and intuition cannot decide what counts as an individual (Hull 1992), the suggestion here is to "ask" the immune system. For example, in the ascidian Botryllus schlosseri, in which individuality appears to be realized both at the zooid and the colony level, an immunological criterion entails that, because reactions of fusion/rejection occur at the level of the colony, it is the colony that counts as a physiological individual ${ }^{12}$. Therefore, the main advantage of an immunological approach is that it leads to a precise definition of physiological individuality, based on the three key arguments that the immune system constitutes a discrimination system, is truly systemic, and is found ubiquitously in the living world (Pradeu 2012).

\section{3. "Organisms" or "biological individuals"?}

A recent - and, in my view, problematic - attitude found in some sectors of evolutionary biology (e.g., Gardner and Grafen 2009; Queller and Strassmann 2009; Folse and Roughgarden 2010) and philosophy of biology (e.g., Clarke 2013) has been to consider the notions of "organism" and "biological individual" as synonymous. ${ }^{13}$ This attitude has one

12 Other examples include the immunological delineation in social insects where, sometimes, the immunological unit is the "superorganism" (Cremer and Sixt 2009; Pradeu 2012).

${ }^{13}$ A partly similar view had already been defended in a landmark paper by (Wilson and Sober 1989), whose aim was to rehabilitate the notion of a "superorganism" (e.g., some ant colonies) and the possibility of group selection. Wilson and Sober proposed to reject the notion of a "biological individual" and to adopt the notion of "organism" or "superorganism" at different biological levels, based on the degree of within-unit and between-unit natural selection: "Natural selection can act both within a unit (favoring some elements of the unit over others) and between units (favoring some units over others). When within-unit selection overwhelms between-unit selection, the unit becomes a collection of organisms without itself having the properties of an organism, in the formal sense of the word. When between-unit selection overwhelms within-unit selection, the unit itself becomes an organism in the formal sense of the word." (Wilson and Sober, op. cit., p. 343). 
advantage but also a significant drawback. The advantage is that it combines physiological considerations with evolutionary considerations - an important aim for biologists and philosophers interested in biological individuality. The drawback, however, is that, instead of really taking into account the lessons that physiological fields have to offer about biological individuality, it tends to reduce physiological individuality to evolutionary considerations. For example, to be part of an "organism" in Queller and Strassmann's (2009, and this special issue) sense requires much more than just strong interactions between interdependent constituents; it requires high cooperation and very low conflict on the long run - two criteria inspired by an evolutionary approach to biological individuality, and where diachronic considerations take priority over synchronic ones. Though criteria such as these are perfectly legitimate as possible criteria for biological individuality, what I want to show is that entities individuated on the basis of physiological criteria (often called "organisms") and entities individuated on the basis of evolutionary criteria (sometimes called "organisms") do not always coincide. So it is confusing to suggest that the entities individuated on the basis of evolutionary criteria are what a long tradition has called "organisms."

Historically, the word "organism" has physiological rather than evolutionary connotations. This historical argument is not decisive, but it is important to have it in mind. The word has its origins in related terms, such as "organization," of course, but also "organic body" and "organized body," in particular in Leibniz and Louis Bourguet (Cheung 2006; Cheung 2010; Duchesneau 2010). "Organism", initially, referred to a certain way of being organized, and not to an individual living body ${ }^{14}$ (Duchesneau 2010). Kant played an important role both in the use of the term "organism" to describe an individual living body, and in defining it as a self-organized entity (Huneman 2006; Kant 2007) - a definition that has been adopted by many biologists and philosophers (e.g., Kauffman 1993; Keller 2007). At the end of the $18^{\text {th }}$ century, "organism" takes the meaning of an individual living body and becomes a technical term in scientific discourse around 1830 (Cheung 2006). The notion of an organism was thus built at a time when evolutionary considerations were scarce, and was used to refer to a unit of functioning, reflecting centuries of thoughts on questions such as part-whole relations (popular since Aristotle and Galen (Lennox 2001)).

During the $19^{\text {th }}$ century, the organism became firmly positioned as a functionallyintegrated whole made of interdependent and interconnected parts. It was considered the task of physiology to describe and explain the processes by which this integration is regulated. Claude Bernard, for instance, saw the complex organism as an aggregate of cells where every element is subject to a regulated control by the whole, as manifested by its capacity to maintain and repair itself (Bernard 1974). Cannon writes that "regulation in the organism is the central problem of physiology" (Cannon 1929). Similarly, for Lwoff (1966) "An organism is an integrated system of interdependent structures and functions." 15

Interestingly, as explained later in this section, Sober himself has held a view close to the "physiological view" defended here.

${ }^{14}$ Leibniz, e.g., replaces "organism" by "organization" in the second version of a letter to Arnauld (1687). He also says that the world is "full of an organism" (and not full of "organisms" in the plural). Similarly, in 1850, Linnaeus (Economy of Nature) writes: "Stones possess no life and organism".

15 Entire quotation: "An organism is an integrated system of interdependent structures and functions. An organism is constituted of cells, and a cell consists of molecules which must work in harmony. Each molecule must know what the others are doing. Each one must be capable of receiving messages and must be sufficiently disciplined to obey." 
Importantly, for Lwoff - as for many present-day microbiologists - the concept of an organism can be applied to unicellular entities as well as to multicellular entities. A unicellular organism, whether eukaryotic or prokaryotic (i.e. with or without a nucleus), can be conceived as a functionally-integrated and cohesive whole, the physiology of which can be studied (e.g., Kim and Gadd 2008). ${ }^{16}$

Most present-day biologists, including many evolutionists, adopt a similar definition of "organism", as a functionally integrated and cohesive whole made of interdependent and interconnected parts (e.g., Wolvekamp 1966; Gould and Lewontin 1979; Bock 1989; Lewontin 2000) - a conception also expressed by philosophers of biology (e.g., Sober 1991; Sober 2000; Ruiz-Mirazo et al. 2000; Godfrey-Smith 2013). Moreover, many biologists insist that the organism is the chief object of physiology. Timothy Buchman (2002), for instance, shows that the aim of physiology at the time of systemic approaches ("systemic physiology") is to understand how the aggregation of cells constitutes a whole organism, via the balance between autonomy and connectedness.

Overall, since the appearance of its modern meaning at the end of the $18^{\text {th }}$ century, the "organism" notion has been used to refer to a cohesive and functionally-integrated biological whole, pertaining first and foremost to the field of physiology (Perlman 2000).

Perhaps one might be tempted to object that this definition of the organism is now outdated, and has been replaced, post-Darwin, by an evolutionary definition. But this would be ill-founded. Evolution has not led to a re-definition of organisms per se, but rather to the idea that the peculiar characteristics of organisms can be explained historically, at least in part, in terms of causes acting at an evolutionary scale (Lewontin 1983; Sober 1991; Pepper and Herron 2008; Queller and Strassmann 2009). Of course, this was already an important aim for Darwin, who, in On the Origin of Species, pays attention to some physiological aspects, such as the "physiological division of labour." At the same time, however, Darwin shows that an approach to the living world based purely on physiology and extant functions can be misleading from an evolutionary point of view, particularly when establishing classifications (e.g., when classifying on the basis of rudimentary organs - a point he examines at length $\left.{ }^{17}\right)$.

Although this argument is not in itself decisive, it is historically much more accurate to use the word "organism" to refer to a physiological individual than to an evolutionary individual. Naturally, one can decide to use "organism" in a way that differs from historical use - e.g., by saying that the "organism" must be understood on purely evolutionary

\footnotetext{
16 Importantly, microbes often cluster into microbial communities called "biofilms," and, at least in some cases, the biofilm seems to exhibit a high degree of biological individuality. But, precisely, it is possible, in those cases, to show that the biofilm expresses a high degree of physiological individuality, that is, it presents itself as a functionally integrated and cohesive metabolic whole, made of interdependent and interconnected parts. See James A. Shapiro, "Thinking about bacterial populations as multicellular organisms," Annual Reviews in Microbiology, 52, 1 (1998): 81-104; Julian W. T. Wimpenny, Sara L. Kinniment and Melanie A. Scourfield, "The physiology and biochemistry of biofilm," in S. P. Denyer, S. P. Gorman and M. Sussman, eds., Microbial Biofilms: Formation and Control (Oxford: Blackwell Scientific Publications, 1993), pp. 5194. On the individuality of biofilms, see also Marc Ereshefsky and Makmiller Pedroso, "Biological individuality: the case of biofilms," Biology and Philosophy, 28, 2 (2013): 331-349.

17 E.g., "as rudimentary organs, by whatever steps they may have been degraded into their present useless condition, are the record of a former state of things, and have been retained solely through the power of inheritance, - we can understand, on the genealogical view of classification, how it is that systematists, in placing organisms in their proper places in the natural system, have often found rudimentary parts as useful as, or even sometimes more useful than, parts of high physiological importance." (On the Origin of Species).
} 
grounds. But, in addition to being at odds with history and common usage, it is misleading to refer to evolutionary individuals as "organisms", since it suggests, inadequately, that evolutionary individuality and physiological individuality always coincide, which is not true - as the final section shows.

\section{Evolutionary individuality and physiological individuality do not always coincide, but can be combined}

The category of a "biological individual" include:

a) The subcategory of an evolutionary individual: a selective unit, that is, an entity that should be considered as one unit from the point of view of natural selection;

b) The subcategory of a physiological individual: a physiological unit, that is, a functionally integrated and cohesive metabolic whole, made of interdependent and interconnected parts.

Calling evolutionary individuals "organisms" gives the impression that evolutionary individuality intrinsically goes with physiological individuality, but this is not always true (Sober 1991; Hull 1992; Pradeu 2010; Godfrey-Smith 2013). In this section, I will show that physiological individuals ("organisms") and evolutionary individuals do not always coincide.

In the traditional conception of evolutionary individuals, inspired by the hierarchical conception of "units of selection" (Lewontin 1970; Gould and Lloyd 1999), organisms constitute just one level in the hierarchy of evolutionary individuals. This is notably the case in multilevel selection theory (Damuth and Heisler 1988; Sober and Wilson 1998; Okasha 2006). An evolutionary individual is characterized by variation, heritability, and differential fitness. Organisms are often instances of evolutionary individuals, but, in some circumstances, genes, chromosomes, organelles, populations, etc. can also be evolutionary individuals. In this conception, organisms are evolutionary individuals, but not all evolutionary individuals are organisms.

In the last three decades, two influential conceptions of evolutionary individuality have been built on the foundations of the traditional hierarchical conception:

(i) the evolutionary individual as an interactor, and

(ii) the evolutionary individual as a Darwinian individual. ${ }^{18}$

To clarify the debate over the "units of selection," Hull suggested distinguishing the replicator (an entity that passes on its structure directly in replication - typically, a gene) and the interactor (an entity whose interaction with its environment leads to the differential copying of the replicators - typically, an organism) (Hull 1980; Lloyd 2012). This suggestion has been criticized (Godfrey-Smith 2009: 31-36), but several authors still find the notion of an interactor useful. This includes those who deny that reproduction is a necessary condition for evolution by natural selection and who consider that persistence can also lead to relevant fitness differences (Bouchard 2008). Are also concerned those who want to insist that natural selection acts sometimes on collaborative units of living entities (e.g., a symbiotic consortium) which are so tightly integrated that they are strictly dependent one on the other for their survival and reproduction (Dupré and O'Malley 2009).

${ }^{18}$ For space reasons, I will not analyse here another concept that has been widely discussed, namely Griesemer's (2000) concept of a reproducer. 
More recently, Godfrey-Smith (2009), building more directly on Lewontin's work (Lewontin 1970), has rejected the replicator/interactor view and suggest we conceive of evolutionary individuality in relation to the notion of a Darwinian individual. A Darwinian individual is a member of a Darwinian population, which itself is a population of objects characterized by variation, heritability and differential fitness. Godfrey-Smith believes that reproduction is essential to evolution by natural selection, and therefore that an evolutionary individual should be understood as a reproductive unit. The key question here is not: Which entities undergo natural selection? (as in the interactor framework), but: Which entities reproduce?

Therefore, the landscape of the different conceptions of biological individuality that coexist in present literature is rather complex, and could be schematically represented as in Figure 2.

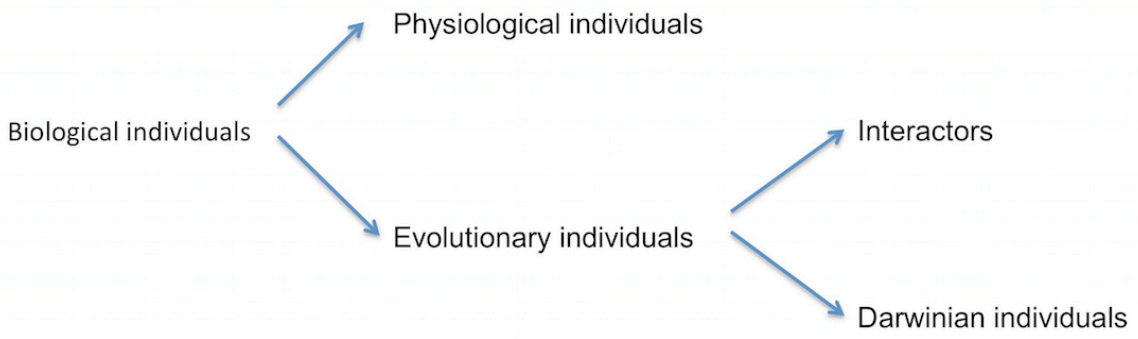

Fig. 2. Two important subcategories of biological individuals. Biological individuals can be physiological individuals or evolutionary individuals. Among evolutionary individuals, one can distinguish interactors and Darwinian individuals.

My aim here is not to take sides in the debate over which conception of evolutionary individuals (interactors or Darwinian individuals) is better. Rather, I intend to show that, whatever conception of evolutionary individuals one adopts, the categories of physiological individuals and evolutionary individuals do not always coincide.

Let us start with Darwinian individuals. Following others (Dupré and O'Malley 2009; Pradeu 2010), Godfrey-Smith shows that "organisms" (as physiological, metabolic units) and "Darwinian individuals" (as reproductive units) are non-identical, only sometimes overlapping, categories (Godfrey-Smith 2013; 2014). Some Darwinian individuals (e.g., chromosomes, viruses) are not organisms. But it is also true that some organisms are not Darwinian individuals. The key for Godfrey-Smith is to pick out the reproductive entities, and thus the entities that constitute lineages. But it is important to recognise that a major result of recent biological research is precisely that very often a physiological individual is not as such a reproducing entity, but rather a local nexus of different lineages of reproducing entities. Indeed, work on symbiosis has shown that virtually all physiological individuals are multispecies units (Pradeu and Carosella 2006; Dupré and O’Malley 2009; Bosch and McFall-Ngai 2011; Pradeu 2012), functionallyintegrated wholes that unify an extraordinarily diverse range of living constituents - in particular bacteria (Bäckhed et al. 2005; Faith et al. 2013), fungi (Underhill and Iliev 2014), and viruses (Virgin 2014). Such a physiological whole does not include as its constituents all the microbes that are in or on the host, only those that both interact strongly with other host's constituents and make a critical contribution to the functioning and survival of the 
whole. This kind of host-microbe associations is ubiquitous. Organisms as diverse as plants, marine animals such as ascidians and corals, insects or mammals, harbour a tremendous number of microbes that play a key role in their physiological activities digestion, immune defence, development, etc. - at least in natural conditions (Bosch and McFall-Ngai 2011; McFall-Ngai et al. 2013; Oldroyd 2013). Germ-free organisms (i.e., organisms raised in the lab, who do not possess normal microbiota) have many physiological defects, and usually cannot live and reproduce normally outside strict laboratory conditions (Xu and Gordon 2003).

If one adopts my immunological perspective on physiological individuality, then the physiological individual admits among its constituents the resident microbes with which its immune system interacts and that it tolerates - regardless of their functional contribution to the whole. I have found this immune-based conception useful, because it does not depend on a definition of terms that are often ambiguous ("functional contribution", "cooperation", "collaboration", "mutualism") (Pradeu 2012). But my point is that, regardless of the conception one adopts (the "immunological" physiological individual or the "functional" physiological individual), the categories of "physiological individuals" and "Darwinian individuals" do not necessarily converge as soon as one realizes that a physiological individual includes at least some members of its microbiota.

When do the terms "physiological individuals" and "Darwinian individuals" refer to different entities? The mode of transmission can make an important difference. In some cases, for instance in arthropods, many members of the microbiota are transmitted vertically (from parents to offspring). In other cases, for instance in mammals and in many plants, a majority of the members of the microbiota are transmitted horizontally (i.e., they are acquired from the environment) (Bright and Bulgheresi 2010) ${ }^{19}$. In the case of vertical transmission, physiological individuals understood as host-microbe associations can be highly-realised Darwinian individuals, because lineages of these associations can be established. But in the case of horizontal transmission, physiological individuals understood as host-microbe associations do not constitute lineages as associations. Rather, those associations are local concentrations of different lineages ${ }^{20}$. For example, a physiologicallydefined human being is the locus of one genetically "human" lineage, and many microbial lineages.

I now turn to interactors (entities whose interaction with their environment leads to the differential copying of the replicators). Are all interactors physiological individuals? No: as Hull showed, genes, chromosomes, organelles, populations, etc. can in some circumstances be interactors, without necessarily being physiological individuals. Conversely, are all physiological individuals "interactors"? Most of them are. But being an interactor comes in degrees, and it can perfectly well happen that a given physiological individual displays a low degree of interactor-like individuality (examples include group selection in some social insects (Wilson and Sober 1989), or strong cellular selection at the

\footnotetext{
19 Contrary to a frequent assumption, horizontal associations are not necessarily more recent and less indispensable for the host than vertical associations (McFall-Ngai 2002; Ebert 2013).

${ }^{20}$ Interestingly, Wilson and Sober (op. cit., p. 348-349) suggested that mutualistic communities such as some phoretic associations could be seen as multi-species superorganisms. I think that the research done on symbiosis in the last ten years has shown that this kind of situation is much more frequent than anyone could have anticipated in 1989, and therefore that an adjustment of Wilson and Sober's view on biological individuality is useful.
} 
levels of cancerous cells in a multicellular organism (Buss 1987)). So many physiological individuals are interactors, but they do not always exhibit the highest level of interactor-like individuality, and in some cases (when selection mainly happens at another level), the physiological individual should not even be considered as an interactor proper.

Therefore, whether one defines "evolutionary individuals" as Darwinian individuals or as interactors, the categories of "physiological individuals" and "evolutionary individuals" do not coincide, and hence I think it is both conceptually and empirically inadequate to use the notions of "evolutionary individuals" and "organisms" interchangeably. Figure 3 presents the different categories of a biological individual.

Why should we distinguish physiological individuals from evolutionary individuals? Firstly, because the distinction itself can do important scientific and philosophical work. The distinction clarifies the fact that biologists interested in identifying biological individuals and/or organisms can have very different practical aims, and raise quite different scientific questions (Pepper and Herron 2008). This further reminds us that we should recognize different biological entities on different grounds, instead of making potential category errors - such as when, for example, viruses are excluded from the category of biological individuals based on the idea that they are not physiological individuals (because they are considered to lack an autonomous metabolism), even though they are perfectly legitimate evolutionary individuals, or when host-microbe associations are not considered as biological individuals based on the idea that they do not constitute evolutionary units, even when they are perfectly legitimate physiological individuals.

Secondly, the distinction is useful because the only satisfying way to produce a unified conception of biological individuality is to combine perspectives that have been distinguished beforehand - instead of reducing one perspective to the other. There are many ways in which such a combination of a physiological and an evolutionary perspective can be useful. One can ask, for instance, which kinds of selective pressures lead to an increase in physiological integration, and which don't (Pepper and Herron 2008). There are clearly different ways to be adapted, some of which will lead to stronger interconnectedness and co-dependence, while others may lead to stronger modularity, particularly when a tight interdependence between parts might be detrimental to survival (Sober 1991).

The combination can also be useful in clarifying our expectations, particularly as to which kind of physiological integration natural selection will tend to favour. For example, it is commonly said that, on the long run, evolution will favour the internalization of symbiotic microbes into the host and their vertical transmission, but what we observe in practice is different: in many cases, such as the ancient and stable legume-rhizobia association, we observe complex intimate interactions, reoccurring in an horizontal way at each generation (Bright and Bulgheresi 2010) (Kiers et al. 2003; Oldroyd 2013), instead of vertical transmission.

Another important task at the physiological-evolutionary interface is to determine the role of physiological unifying processes, for example the immune system, in major transitions in evolution, particularly in so-called "policing" mechanisms (Michod 1999; Pradeu 2013). It is possible than an analogue of an immune system (a recognition and integration-rejection system) has been required for many evolutionary transitions. ${ }^{21}$

${ }^{21}$ Interestingly, some models of biological entities switching from a unicellular to a multicellular state can be useful to better explore this issue. For example, it has been shown that, when the multicellular stage ("slug") 
Based on the combination of physiological and evolutionary individuality, one can build a two axis-diagram, one axis corresponding to physiological individuality, the other to evolutionary individuality, with the aim of assessing an overall "score" of biological individuality. If the views defended in this paper are correct, then an insect with its vertically-transmitted microbiota will be both a physiological individual and an evolutionary individual to a high degree, whereas a human being with its horizontallytransmitted microbiota will be a physiological individual to a high degree, but will score low as an evolutionary individual. This might be seen as a useful antidote to the many views that, in the past, have suggested that "we" (humans) are always the most highly individuated living things.

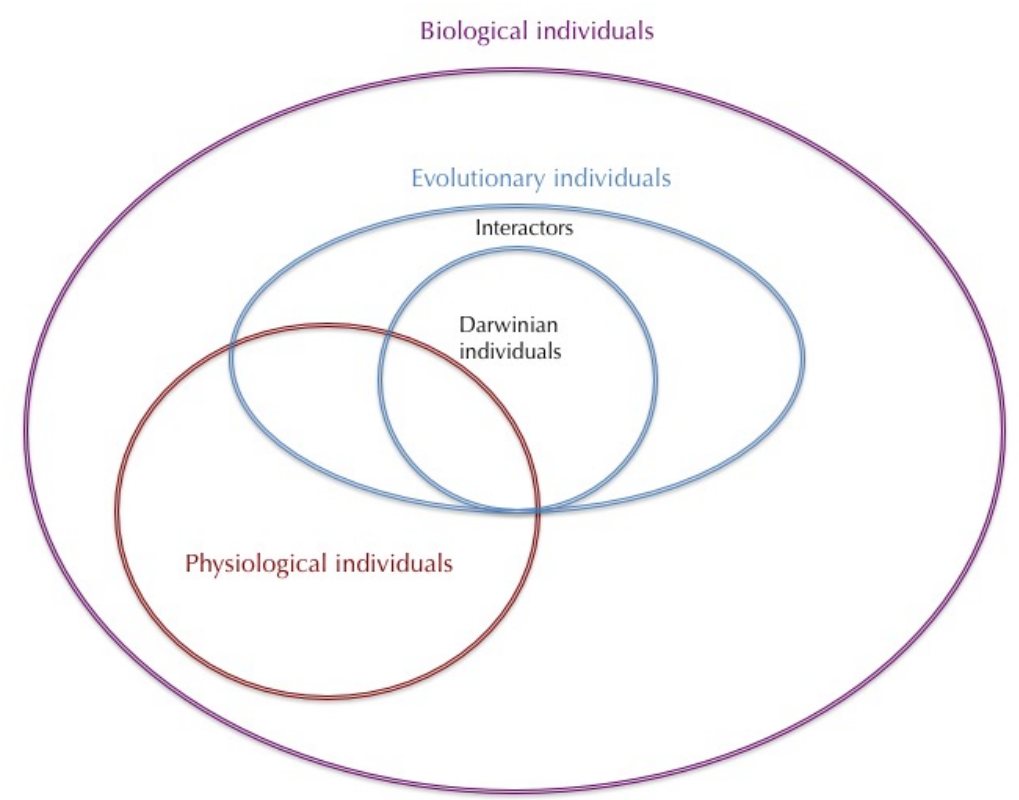

Fig. 3. Relations among the different subcategories of biological individuals. The category of a "biological individual" includes several subcategories, including the two subcategories of a "physiological individual" (in red), and an "evolutionary individual" (in blue). Evolutionary individuals themselves are divided into "Darwinian individuals" and "interactors." Not all organisms are Darwinians individuals, and neither are all organisms interactors. Please note that all Darwinian individuals in Godfrey-Smith's sense (reproductive units) are "interactors" (selective units), but not vice versa (this is to be expected, since criteria to be a Darwinian individual are more demanding: a Darwinian individual is a selective unit that reproduces in a specific way).

\section{Conclusion}

The concept of biological individuality includes both evolutionary individuality (Darwinian individuals or interactors) and physiological individuality. Conflating the notions of "biological individuals" and "organisms" is confusing, both, generally, because it rides

of Dictyostelium discoideum is constituted, some cells specialize in an immune phagocytic activity (Chen et al. 2007), a question now explored by Queller and Strassmann, and others (Brock et al. 2016). 
roughshod over the various examinations of individuality in different biological fields, and, more specifically, because it inadequately suggests that physiological individuality and evolutionary individuality necessarily coincide. I have claimed that what is needed is a clear examination of the specificities of the physiological approaches and the evolutionary approaches to biological individuality, with the aim of confronting and combining them so as to construct a more precise and integrative conception of biological individuality. Though this paper restricts itself, primarily, to the disciplines of immunology and evolution, the hope is that future philosophers of biology will build a much more unified account of biological individuality by integrating a broader spectrum of biological fields.

\section{Acknowledgements}

I thank Leonardo Bich, Ellen Clarke, John Dupré, Marc Ereshefsky, Adam Ferner, Scott Gilbert, Peter Godfrey-Smith, Philippe Huneman, Richard Lewontin, Margaret McFallNgai, Maureen O’Malley, Alessandro Minelli, Makmiller Pedroso, and Elliott Sober for comments on previous drafts of this paper. This project has received funding from the European Research Council (ERC) under the European Union's Horizon 2020 research and innovation programme - grant agreement $n^{\circ} 637647$ - IDEM.

\section{References}

Anderton SM, Wraith DC (2002) Selection and fine-tuning of the autoimmune T-cell repertoire. Nat Rev Immunol 2:487-498. doi: 10.1038/nri842

Arnellos A, Moreno A, Ruiz-Mirazo K (2013) Organizational requirements for multicellular autonomy: insights from a comparative case study. Biol Philos 29:851-884. doi: 10.1007/s10539-013-9387-x

Bäckhed F, Ley RE, Sonnenburg JL, et al (2005) Host-Bacterial Mutualism in the Human Intestine. Science 307:1915-1920. doi: 10.1126/science.1104816

Bechtel W (2006) Discovering cell mechanisms: the creation of modern cell biology. Cambridge University Press, New York

Bernard C (1974) Lectures on the phenomena of life common to animals and plants. Thomas, Springfield, Ill

Bernard C (1957) An introduction to the study of experimental medicine. Dover

Publications, New York

Bock WJ (1989) Organisms as Functional Machines: A Connectivity Explanation. Am Zool 29:1119-1132.

Bosch TCG, McFall-Ngai MJ (2011) Metaorganisms as the new frontier. Zool Jena Ger 114:185-190. doi: 10.1016/j.zool.2011.04.001

Bouchard F (2008) Causal Processes, Fitness, and the Differential Persistence of Lineages. Philos Sci 75:560-570. doi: 10.1086/594507

Bouchard F, Huneman P (2013) From Groups to Individuals: Perspectives on Biological Associations and Emerging Individuality. MIT Press, Cambridge, MA

Bouneaud C, Kourilsky P, Bousso P (2000) Impact of negative selection on the T cell repertoire reactive to a self-peptide: a large fraction of $\mathrm{T}$ cell clones escapes clonal deletion. Immunity 13:829-840.

Bright M, Bulgheresi S (2010) A complex journey: transmission of microbial symbionts. Nat Rev Microbiol 8:218-230. doi: 10.1038/nrmicro2262 
Brock DA, Callison WÉ, Strassmann JE, Queller DC (2016) Sentinel cells, symbiotic bacteria and toxin resistance in the social amoeba Dictyostelium discoideum. Proc R Soc B 283:20152727. doi: 10.1098/rspb.2015.2727

Buchman TG (2002) The community of the self. Nature 420:246-251. doi:

10.1038/nature01260

Burnet FM (1962) The Integrity of the Body: A Discussion of Modern Immunological Ideas. Harvard University Press, Cambridge, MA

Burnet FM (1960) Immunological recognition of self. Nobel Lect Physiol Med 3:689-701. Burnet FM (1969) Cellular Immunology: Self and Notself. Cambridge University Press, Cambridge

Buss LW (1987) The Evolution of Individuality. Princeton University Press, Princeton, N.J. Canguilhem G (1994a) [1963] La constitution de la physiologie comme science. In: Etudes d'histoire et de philosophies des sciences concernant les vivants et la vie. Vrin, Paris, pp 226-273

Canguilhem G (1994b) [1966] Le tout et la partie dans la pensée biologique. In: Etudes d'histoire et de philosophie des sciences concernant le vivant et la vie. Vrin, Paris, pp 319333

Cannon WB (1926) Physiological regulation of normal states. Some tentative postulates concerning biological homeostasis. In: Pettit A (ed) À Charles Richet, ses amis, ses collègues, ses élèves. Les Editions médicales, Paris, pp 91-93

Cannon WB (1929) Organization for Physiological Homeostasis. Physiol Rev 9:399-431.

Chen G, Zhuchenko O, Kuspa A (2007) Immune-like phagocyte activity in the social amoeba. Science 317:678-681. doi: 10.1126/science.1143991

Cheung T (2006) From the organism of a body to the body of an organism: occurrence and meaning of the word "organism" from the seventeenth to the nineteenth centuries. Br J Hist Sci 39:319-339.

Cheung T (2010) What is an "Organism"? On the Occurrence of a New Term and Its Conceptual Transformations 1680-1850. Hist Philos Life Sci 32:155-194.

Child CM (1915) Individuality in organisms. The University of Chicago press, Chicago, Ill. Chu H, Mazmanian SK (2013) Innate immune recognition of the microbiota promotes hostmicrobial symbiosis. Nat Immunol 14:668-675. doi: 10.1038/ni.2635

Clarke E (2011) The Problem of Biological Individuality. Biol Theory 5:312-325. Clarke E (2013) The Multiple Realizability of Biological Individuals. J Philos 413-435. Cohen IR (2000) Tending Adam's Garden: Evolving the Cognitive Immune Self. Academic Press, San Diego

Cooper SJ (2008) From Claude Bernard to Walter Cannon. Emergence of the concept of homeostasis. Appetite 51:419-427. doi: 10.1016/j.appet.2008.06.005

Cowley AW (2003) Genomics and homeostasis. Am J Physiol Regul Integr Comp Physiol 284:R611-627. doi: 10.1152/ajpregu.00567.2002

Cremer S, Sixt M (2009) Analogies in the evolution of individual and social immunity.

Philos Trans R Soc Lond B Biol Sci 364:129-142. doi: 10.1098/rstb.2008.0166

Damuth J, Heisler IL (1988) Alternative formulations of multilevel selection. Biol Philos 3:407-430. doi: 10.1007/BF00647962

Dausset J (1981) The major histocompatibility complex in man. Science 213:1469-1474. doi: $10.1126 /$ science. 6792704

DiBona GF (2005) Physiology in perspective: The Wisdom of the Body. Neural control of the kidney. Am J Physiol Regul Integr Comp Physiol 289:R633-641. doi: 
10.1152/ajpregu.00258.2005

Duchesneau F (1987) Genèse de la théorie cellulaire. Bellarmin ; Vrin, Montréal : Paris Duchesneau F (2010) Leibniz: le vivant et l'organisme. J. Vrin, Paris Dupré J, O'Malley M (2009) Varieties of Living Things: Life at the Intersection of Lineage and Metabolism. Philos Theory Biol. doi: http://dx.doi.org/10.3998/ptb.6959004.0001.003 Ebert D (2013) The Epidemiology and Evolution of Symbionts with Mixed-Mode Transmission. Annu Rev Ecol Evol Syst 44:623-643. doi: 10.1146/annurev-ecolsys032513-100555

Eldredge N (1984) Large-Scale Biological Entities and the Evolutionary Process. PSA Proc Bienn Meet Philos Sci Assoc 1984:551-566. doi:

10.1086/psaprocbienmeetp.1984.2.192526

Faith JJ, Guruge JL, Charbonneau M, et al (2013) The Long-Term Stability of the Human Gut Microbiota. Science 341:1237439. doi: 10.1126/science.1237439

Folse HJ, Roughgarden J (2010) What is an Individual Organism? A Multilevel Selection Perspective. Q Rev Biol 85:447-472.

Gardner A, Grafen A (2009) Capturing the superorganism: a formal theory of group adaptation. J Evol Biol 22:659-671. doi: 10.1111/j.1420-9101.2008.01681.x Germain RN (2012) Maintaining system homeostasis: the third law of Newtonian immunology. Nat Immunol 13:902-906. doi: 10.1038/ni.2404 Gilbert SF, Sapp J, Tauber AI (2012) A symbiotic view of life: we have never been individuals. Q Rev Biol 87:325-341.

Godfrey-Smith P (2009) Darwinian populations and natural selection. Oxford University Press, Oxford

Godfrey-Smith P (2013) Darwinian Individuals. In: Bouchard F, Huneman P (eds) From Groups to Individuals: evolution and emerging individuality. MIT Press, Cambridge, MA, pp 17-36

Godfrey-Smith P (2014) Philosophy of biology. Princeton University Press, 2014,

Princeton

Gottlieb G (1992) Individual development and evolution: the genesis of novel behavior. Oxford University Press, New York

Gould SJ, Lewontin RC (1979) The Spandrels of San Marco and the Panglossian Paradigm: A Critique of the Adaptationist Programme. Proc R Soc Lond B Biol Sci 205:581-598. doi: 10.1098/rspb.1979.0086

Gould SJ, Lloyd EA (1999) Individuality and adaptation across levels of selection: How shall we name and generalize the unit of Darwinism? Proc Natl Acad Sci 96:11904-11909. doi: 10.1073/pnas.96.21.11904

Griesemer J (2000) Development, Culture, and the Units of Inheritance. Philos Sci 67:S348-S368. doi: 10.1086/392831

Guay A, Pradeu T (2016) Individuals Across the Sciences. Oxford University Press, New York

Haldane JS (1929) Claude Bernard's conception of the internal environment. Science 69:453-454. doi: 10.1126/science.69.1791.453

Hamburger J (1978) Discovering the individual: a fascinating journey to new frontiers of immunology and genetics, 1 st ed. Norton, New York

Herron MD, Rashidi A, Shelton DE, Driscoll WW (2013) Cellular differentiation and individuality in the "minor" multicellular taxa. Biol Rev Camb Philos Soc 88:844-861. doi: $10.1111 /$ brv.12031 
Holmes FL (1986) Claude Bernard, The "Milieu Intérieur", and Regulatory Physiology. Hist Philos Life Sci 8:3-25.

Hooper LV, Gordon JI (2001) Commensal host-bacterial relationships in the gut. Science 292:1115-1118.

Hull D (1980) Individuality and Selection. Annu Rev Ecol Syst 11:311-332. doi:

10.1146/annurev.es.11.110180.001523

Hull D (1992) Individual. In: Keller EF, Lloyd EA (eds) Keywords in Evolutionary

Biology. Harvard University Press, Cambridge, MA, pp 181-187

Hull DL (1978) A Matter of Individuality. Philos Sci 45:335-360.

Huneman P (2014) Individuality as a Theoretical Scheme. II. About the Weak Individuality

of Organisms and Ecosystems. Biol Theory 9:374-381. doi: 10.1007/s13752-014-0193-8

Huneman P (2006) Naturalising purpose: from comparative anatomy to the "adventure of reason." Stud Hist Philos Biol Biomed Sci 37:649-674. doi: 10.1016/j.shpsc.2006.09.004 Jerne NK (1974) Towards a network theory of the immune system. Ann Immunol 125C:373-389.

Kant I (2007) Critique of judgement. Oxford University Press, Oxford ; New York Kauffman SA (1993) The origins of order: self organization and selection in evolution. Oxford University Press, New York

Keller EF (2007) The disappearance of function from "self-organizing systems." In: Boogerd F (ed) Systems Biology: Philosophical Foundations. Elsevier, Amsterdam, pp 303-317

Kiers ET, Rousseau RA, West SA, Denison RF (2003) Host sanctions and the legumerhizobium mutualism. Nature 425:78-81. doi: 10.1038/nature01931

Kim BH, Gadd GM (2008) Bacterial physiology and metabolism. Cambridge University Press, Cambridge; New York

Kotas ME, Medzhitov R (2015) Homeostasis, Inflammation, and Disease Susceptibility. Cell 160:816-827. doi: 10.1016/j.cell.2015.02.010

Lennox JG (2001) Aristotle's philosophy of biology: studies in the origins of life science. Cambridge University Press, Cambridge, UK ; New York

Lewontin RC (1983) The Organism as the Subject and Object of Evolution. Scientia 77:65. Lewontin RC (1970) The Units of Selection. Annu Rev Ecol Syst 1:1-18. doi:

10.1146/annurev.es.01.110170.000245

Lewontin RC (2000) The triple helix: gene, organism, and environment. Harvard University Press, Cambridge, Mass

Lloyd E (2012) Units and Levels of Selection. In: Zalta EN (ed) The Stanford Encyclopedia of Philosophy, Winter 2012.

Loeb L (1930) Transplantation and Individuality. Physiol Rev 10:547-616.

Loeb L (1937) The Biological Basis of Individuality. Science 86:1-5.

Loeb L (1953) Organismal Differentials and Organ Differentials. Proc Natl Acad Sci U S A 39:127-134.

Loeb L (1945) The Biological Basis of Individuality. Thomas, Springfield Löwy I (1991) The Immunological Construction of the Self. In: Tauber AI (ed) Organism and the origins of self. Kluwer, Dordrecht, pp 3-75

Löwy I (2003) On guinea pigs, dogs and men: anaphylaxis and the study of biological individuality, 1902-1939. Stud. Hist. Philos. Biol. Biomed. Sci. 399-423.

Lüscher M (1961) Air-Conditioned Termite Nests. Sci Am 205:138-145. doi: 10.1038/scientificamerican0761-138 
Lwoff A (1966) Interaction among virus, cell, and organism. Science 152:1216-1220. McFall-Ngai M, Hadfield MG, Bosch TCG, et al (2013) Animals in a bacterial world, a new imperative for the life sciences. Proc Natl Acad Sci U S A 110:3229-3236. doi: 10.1073/pnas.1218525110

McFall-Ngai MJ (2002) Unseen Forces: The Influence of Bacteria on Animal

Development. Dev Biol 242:1-14. doi: 10.1006/dbio.2001.0522

Medawar PB (1957) The Uniqueness of the Individual. Methuen, Londres

Michod RE (1999) Darwinian dynamics : evolutionary transitions in fitness and individuality. Princeton University Press, Princeton, NJ

Minelli A (2011) Animal Development, an Open-Ended Segment of Life. Biol Theory 6:415. doi: 10.1007/s13752-011-0002-6

Moulin A-M (1991) Le Dernier langage de la médecine. PUF, Paris

Noble D (2008) Claude Bernard, the first systems biologist, and the future of physiology. Exp Physiol 93:16-26. doi: 10.1113/expphysiol.2007.038695

Noble D (2006) The music of life: biology beyond the genome. Oxford University Press, Oxford; New York

Okabe Y, Medzhitov R (2016) Tissue biology perspective on macrophages. Nat Immunol 17:9-17. doi: 10.1038/ni.3320

Okasha S (2006) Evolution and the Levels of Selection. Clarendon Press; Oxford

University Press, Oxford; NY

Oldroyd GED (2013) Speak, friend, and enter: signalling systems that promote beneficial symbiotic associations in plants. Nat Rev Microbiol 11:252-263. doi: 10.1038/nrmicro2990 Pepper JW, Herron MD (2008) Does biology need an organism concept? Biol Rev Camb Philos Soc 83:621-627. doi: 10.1111/j.1469-185X.2008.00057.x

Perlman RL (2000) The Concept of the Organism in Physiology. Theory Biosci 119:174186. doi: 10.1078/1431-7613-00015

Pradeu T (2012) The Limits of the Self: Immunology and Biological Identity. Oxford University Press, New York

Pradeu T (2010) What is an organism? An immunological answer. Hist Philos Life Sci 32:247-268.

Pradeu T (2008) Qu'est-ce qu'un individu biologique? In: Ludwig P, Pradeu T (eds)

L'Individu: perspectives contemporaines. Vrin, Paris,

Pradeu T (2013) Immunity and the emergence of individuality. In: Bouchard F, Huneman P (eds) From Groups to Individuals: Evolution and Emerging Individuality. MIT Press, Cambridge, MA, pp 77-96

Pradeu T (2016) Editorial introduction: The many faces of biological individuality. Biol Philos, this special issue.

Pradeu T, Carosella E (2006) The self model and the conception of biological identity in immunology. Biol Philos 21:235-252.

Queller DC, Strassmann JE (2009) Beyond society: the evolution of organismality. Philos

Trans R Soc Lond B Biol Sci 364:3143-3155. doi: 10.1098/rstb.2009.0095

Richet C (1913) Anaphylaxis.

Richet CR (1894) La défense de l'organisme: cours de physiologie de la Faculté de médecine (1893-1894). Typographie Chamerot et Renouard, Paris

Rowland NE (1998) Brain mechanisms of mammalian fluid homeostasis: insights from use of immediate early gene mapping. Neurosci Biobehav Rev 23:49-63.

Ruiz-Mirazo K, Etxeberria A, Moreno A, Ibáñez J (2000) Organisms and their place in 
biology. Theory Biosci 119:209-233. doi: 10.1078/1431-7613-00018

Sakaguchi S (2000) Regulatory T Cells: Key Controllers of Immunologic Self-Tolerance. Cell 101:455-458. doi: 10.1016/S0092-8674(00)80856-9

Sakaguchi S (2006) Regulatory T cells: Meden Agan. Immunol Rev 212:5-7. doi:

10.1111/j.0105-2896.2006.00425.x

Saladin K (2011) Anatomy \& Physiology: The Unity of Form and Function, 6 edition.

McGraw-Hill Science/Engineering/Math, New York, NY

Sansonetti PJ, Medzhitov R (2009) Learning tolerance while fighting ignorance. Cell 138:416-420. doi: 10.1016/j.cell.2009.07.024

Santelices null (1999) How many kinds of individual are there? Trends Ecol Evol 14:152155.

Savill J, Dransfield I, Gregory C, Haslett C (2002) A blast from the past: clearance of apoptotic cells regulates immune responses. Nat Rev Immunol 2:965-975. doi:

$10.1038 /$ nri957

Seeley TD (1995) The wisdom of the hive: the social physiology of honey bee colonies.

Harvard University Press, Cambridge, Mass.

Sober E (1991) Organisms, Individuals, and Units of Selection. In: Tauber AI (ed)

Organism and the Origins of Self. Springer Netherlands, Dordrecht, pp 275-296

Sober E (1984) The nature of selection: evolutionary theory in philosophical focus. MIT

Press, Cambridge, Mass

Sober E (2000) Philosophy of Biology, 2nd edition. Westview Press

Sober E, Wilson DS (1998) Unto others: the evolution and psychology of unselfish

behavior. Harvard University Press, Cambridge, Mass.

Stefanová I, Dorfman JR, Germain RN (2002) Self-recognition promotes the foreign

antigen sensitivity of naive T lymphocytes. Nature 420:429-434. doi: 10.1038/nature01146

Tauber AI (1991) Organism and the Origins of Self. Kluwer, Dordrecht

Tauber AI (1994) The Immune Self: Theory or Metaphor? Cambridge University Press, Cambridge

Taylor PR, Martinez-Pomares L, Stacey M, et al (2004) Macrophage receptors and immune recognition. Annu Rev Immunol 23:901-944. doi:

10.1146/annurev.immunol.23.021704.115816

Turner JS (2000) The extended organism: the physiology of animal-built structures.

Harvard University Press, Cambridge, Mass

Tyson JJ, Chen K, Novak B (2001) Network dynamics and cell physiology. Nat Rev Mol Cell Biol 2:908-916. doi: 10.1038/35103078

Underhill DM, Iliev ID (2014) The mycobiota: interactions between commensal fungi and the host immune system. Nat Rev Immunol 14:405-416. doi: 10.1038/nri3684

Virchow R (1978) [1858] Cellular pathology as based upon physiological and pathological histology, Special ed. Classics of Medicine Library, Birmingham, Ala.

Virgin HW (2014) The virome in mammalian physiology and disease. Cell 157:142-150.

doi: 10.1016/j.cell.2014.02.032

Walz W (2005) Integrative physiology in the proteomics and post-genomics age. Totowa, NJ: Humana Press, 2005

West SA, Kiers ET (2009) Evolution: what is an organism? Curr Biol CB 19:R1080-1082. doi: 10.1016/j.cub.2009.10.048

Wilson DS, Sober E (1989) Reviving the superorganism. J Theor Biol 136:337-356.

Wilson J (1999) Biological individuality : the identity and persistence of living entities. 
Cambridge University Press, Cambridge \& New York

Wilson RA (2005) Genes and the agents of life: The individual in the fragile sciences, biology. Cambridge University Press, Cambridge \& New York

Wilson RA, Barker M (2013) The Biological Notion of Individual. In: Zalta EN (ed) The Stanford Encyclopedia of Philosophy, 2016th edn.

Wing K, Sakaguchi S (2010) Regulatory T cells exert checks and balances on self tolerance and autoimmunity. Nat Immunol 11:7-13. doi: 10.1038/ni.1818

Wolvekamp HP (1966) The Concept of the Organism as an Integrated Whole. Dialectica 20:196-214.

Wynn TA, Chawla A, Pollard JW (2013) Macrophage biology in development, homeostasis and disease. Nature 496:445-455. doi: 10.1038/nature12034

$\mathrm{Xu}$ J, Gordon JI (2003) Honor thy symbionts. Proc Natl Acad Sci 100:10452-10459. doi: 10.1073 /pnas. 1734063100

Zehn D, Bevan MJ (2006) T cells with low avidity for a tissue-restricted antigen routinely evade central and peripheral tolerance and cause autoimmunity. Immunity 25:261-270. doi: 10.1016/j.immuni.2006.06.009 